\title{
Mercado mundial, dinheiro mundial e moeda inconversível: notas a partir de $\mathbf{O}$ capital
}

\section{Resumo:}

Flávio Ferreira de Miranda ${ }^{1}$

Este artigo parte da demonstração de que a essência do mercado mundial reside nas transferências internacionais de mais-valor. Entendemos que a análise do desenvolvimento histórico do dinheiro mundial, cujos movimentos refletem os movimentos do mais-valor no mercado mundial, deve jogar luz sobre importantes aspectos da concorrência internacional. Em especial, debruçamo-nos sobre a forma contemporânea do dinheiro mundial. Demonstramos o caráter necessário do abandono do padrão metálico para o processo de acumulação de capital, relacionando-o a algumas características marcantes desta fase histórica. Tal análise serve de base para a descrição científica dos mecanismos subjacentes às formas contemporâneas de transferência de mais-valor, sobretudo, do aumento da importância relativa de suas facetas financeiras.

Palavras-chave: Marx; lei do valor; mercado mundial; dinheiro mundial; desenvolvimento desigual.

\section{World Market, world Money and inconvertible currency : notes from Capital}

\begin{abstract}
:
This article takes as its starting point the demonstration that the essence of the world market lies in international transfers of more value. We understand that the analysis of the historical development of world money, whose movements reflect the movements of higher value in the world market, must shed light on important aspects of international competition. Specifically, we look at the contemporary form of world money. We demonstrate the necessary character of the abandonment of the metallic pattern for the process of capital accumulation, Relating it to some outstanding characteristics of this historical phase. Such an analysis serves as a basis for the scientific description of the mechanisms underlying contemporary forms of transfer of value, particularly the increasing relative importance of its financial facets.
\end{abstract}

Key words: Marx; law of value; world market; world money; unequal development.

\footnotetext{
${ }^{1}$ Doutor, professor adjunto da Universidade Federal Rural do Rio de J aneiro (UFRRJ ). E-
} mail: flavioferreiramiranda@hotmail.com. 
É de grande controvérsia, fonte das mais diversas interpretações, a temática dos mecanismos de funcionamento do modo de produção capitalista em escala global. Em especial para a corrente teórica que se propõe a avançar na compreensão das legalidades subjacentes à sociabilidade econômica burguesa: o marxismo. Como era de se esperar, o desenvolvimento histórico do capitalismo, com o consequente aprofundamento de suas tendências e contradições gerais, coloca novas questões para o que genericamente se costuma inserir na rubrica "teorias do imperialismo". Ou seja, para além de seu caráter histórico, o próprio modo de produção capitalista possui uma historicidade que corresponde, em linhas gerais, ao desenrolar dialético de suas tendências gerais, que, contudo, põe-se (e se repõe), em diferentes contextos, de modos profundamente desiguais. Este artigo tem o propósito de discutir uma transformação fundamental nas condições da concorrência intercapitalista em nível mundial - o abandono do padrão monetário dólar-ouro e a consequente emergência de uma forma "desmaterializada" de dinheiro - à luz do que entendemos como a essência das complexas relações que conformam o mercado mundial - ou, se preferirem, do imperialismo: as transferências internacionais de mais-valor.

Nesse sentido, assumimos como tarefa inicial precisamente a demonstração de que a essência do mercado mundial reside nas transferências internacionais de mais-valor, tendo a concorrência como seu lugar teórico. Partindo destas bases, entendemos que a análise do desenvolvimento histórico do dinheiro mundial, cujos movimentos refletem os movimentos do mais-valor no mercado mundial, deve jogar luz sobre importantes aspectos da concorrência internacional. Mais especificamente, debruçamo-nos sobre a forma contemporânea do dinheiro mundial, o chamado padrão dólar-dólar, um aspecto fundamental da fase do capitalismo inaugurada nos anos 1970.

Abrimos essa frente apresentando nossa leitura sobre a forma como Marx entendia o "dinheiro" em geral e, mais especificamente, o "dinheiro mundial". Esta discussão é pressuposto para a análise da forma contemporânea do dinheiro a partir da lei marxiana do valor. Pretendemos demonstrar que a forma não-metálica do dinheiro corresponde a uma possibilidade contida no próprio conceito de valor e, em seguida, apresentar seu advento como necessidade decorrente do desenvolvimento contraditório do modo de produção capitalista, que se efetivou em condições históricas específicas. Finalmente, argumentamos pela relevância da teoria marxiana do valor para se compreender o dinheiro desmaterializado à medida que discutimos alguns de seus aspectos essenciais que, segundo acreditamos, podem servir de base para o estudo 
das formas contemporâneas de transferência de mais-valor no mercado mundial ${ }^{2}$.

\section{Lei do valor e mercado mundial}

Como se sabe, Marx não trata do modo de produção capitalista no nível de abstração das determinações postas pela interação entre distintos capitais nacionais no mercado mundial. Além disso, o autor aponta, no "Prefácio" à primeira edição de sua principal obra, que a necessidade de se compreender o movimento real do modo de produção capitalista, vis-à-vis a impossibilidade de isolamento em laboratório de suas determinações essenciais a fim de observá-las livres de perturbações, impõe o recurso à análise do "caso clássico" de seu desenvolvimento (MARX, 2013, p. 78).

Não obstante, se ao seguir o caminho da concreção da análise de $\mathrm{O}$ capital, para além de seu escopo, desembocamos na relação dialética entre mercados nacionais e mercado mundial ${ }^{3}$, podemos colocar esta questão nos termos da relação entre o "caso clássico" e os casos não-clássicos do desenvolvimento da sociedade burguesa. Isto é, trata-se de compreender a maneira pela qual as tendências gerais, descobertas quando tomado por ilustração o "caso clássico, apresentam-se, de modo mais complexo, no mercado mundial.

O desenvolvimento clássico do capitalismo teve lugar quando uma complexa interação das forças internas à sociedade inglesa pôs o modo de produção capitalista como realização casual de possibilidades concretas. Nesse sentido, este desenvolvimento prescindiu "da intervenção de uma violência externa" (LUKÁCS, 2012, p. 377). Com isso, não se quer dizer que não tenha sido permeado por atos extremamente violentos, no entanto, seguindo uma vez mais Lukács, há "uma diferença qualitativa entre o caso no qual a violência é um momento, é órgão executivo do desenvolvimento direto das forças econômicas, e aquele no qual ela cria condições inteiramente novas para a economia" (LUKÁCS, 2012, pp. 377-8).

No Livro I de O capital, Marx analisa momentos de violência extraeconômica absolutamente necessários para a emergência do modo de

\footnotetext{
2 No entanto, foge ao escopo deste trabalho a tarefa extremamente importante de abordar as diversas formas concretas pelas quais tomam lugar os fluxos internacionais de maisvalor, assim como suas transformações históricas.

3 Em comentário à obra do protecionista estadunidense Carey, diz Marx: "Todas as relações que lhe parecem harmônicas no interior de determinadas fronteiras nacionais ou, inclusive, na forma abstrata de relações universais da sociedade (...), parecem-lhe desarmônicas ali onde se apresentam em sua forma mais desenvolvida - em sua forma de mercado mundial (...). O que Carey não compreende é que essas desarmonias do mercado mundial são unicamente as expressões adequadas últimas das desarmonias que [são] fixadas nas categorias econômicas como relações fixas ou que têm uma existência local em menor escala." (MARX, 2011, p. 30, adendo do editor)
} 
produção capitalista. Nesse tocante, apenas "na Inglaterra, e por isso tomamos esse país como exemplo, tal expropriação se apresenta em sua forma clássica” (MARX, 2013, p. 788). Isto é, neste país, a violência extraeconômica se apresentou como um "órgão executivo do desenvolvimento direto das forças econômicas" burguesas". No entanto, como complementa alguns anos depois, na edição francesa de $\mathrm{O}$ capital:

todos os outros países da Europa Ocidental percorreram o mesmo caminho, ainda que, segundo o meio, ele mude de coloração local, ou se restrinja a um círculo mais estreito, ou apresente um caráter menos pronunciado, ou siga uma ordem de sucessão diferente (MARX, 2013, p. 788).

Simetricamente, nos países de desenvolvimento capitalista nãoclássico, a forma burguesa de sociabilidade só se pôde afirmar pela conquista externa. Isto é, como subproduto da expansão do capitalismo “clássico". Na maioria destes casos, apenas a dominação estrangeira, sempre barbaramente violenta, pôde forjar as novas condições de produção e distribuição. Trata-se de um tipo de relação que subordina e reproduz de modo contínuo e ampliado essa subordinação.

O que importa apontar brevemente nesta seção é o sentido econômico da relação estabelecida entre países que se inserem de forma distinta no mercado mundial, isto é, como as condições econômicas de uns e outros se condicionam reciprocamente. O mercado mundial, diz Marx, "não é só o mercado interno na relação com todos os mercados estrangeiros existentes fora dele, mas é simultaneamente o [mercado] interno de todos os mercados estrangeiros como partes integrantes, por sua vez, do mercado nacional" (MARX, 2011, p. 219, adendo do editor). Nesse sentido, nele resplandecem os diferentes graus de desenvolvimento das forças produtivas em diferentes nações.

O modo como opera a lei do valor no mercado mundial determina uma forma específica de relações internacionais. Como se sabe, é na interação entre capitais distintos que as tendências imanentes ao modo de produção capitalista aparecem para cada capital individual "como uma coerção imposta por capital alheio" (MARX, 2011, p. 338, grifo do autor). Marx chama esta complexa inter-relação entre os diversos capitais existentes de concorrência. Em suas palavras:

Conceitualmente, a concorrência nada mais é do que a natureza interna do capital, sua determinação essencial, que se manifesta e se realiza como ação recíproca dos vários capitais uns sobre os

\footnotetext{
${ }^{4}$ Além disso, no seio do modo de produção burguês "A violência extraeconômica, direta, continua, é claro, a ser empregada, mas apenas excepcionalmente. Para o curso usual das coisas, é possível confiar o trabalhador às leis naturais da produção', isto é, à dependência em que ele mesmo se encontra em relação ao capital, dependência que tem origem nas próprias condições de produção e que por elas é garantida e perpetuada." (MARX, 2013, pp. 808-9).
} 
outros, a tendência interna como necessidade externa (...). O capital existe e só pode existir como muitos capitais e, consequentemente, a sua autodeterminação aparece como ação recíproca desses capitais uns sobre os outros. (MARX, 2011, grifos do autor)

Se no mercado mundial os capitais distintos interagem (com o perdão da redundância) mundialmente, é nos marcos da concorrência que se deve desenvolver este tema. Trabalhar a questão da concorrência significa, ademais, romper o nível de abstração do "capital em geral" 5 tal qual faz Marx a partir da Seção 3 do Livro III de O capital e, pontualmente, para demonstrar o aumento da produtividade como tendência imanente ao capital, nos capítulos X e XXIII do Livro I. Esta análise resulta da separação entre produção e apropriação do mais-valor para cada capital singular, isto é, um capital não necessariamente se apropria de todo o mais-valor criado por ele mesmo ou, por outro lado, pode apropriar-se de quantia de mais-valor maior do que ele próprio produziu. O ponto, portanto, é o da transferência intercapitalista do maisvalor. Como aponta em breve nota ao final dos Grundrisse:

Tendo em vista que o lucro pode ser inferior ao mais-valor, ou seja, que o capital [pode] trocar-se lucrativamente sem se valorizar no sentido estrito, segue-se que não só os capitalistas individuais, mas também as nações podem trocar continuamente entre si, e repetir continuamente a troca em escala sempre crescente, sem que por isso precisem ganhar de modo uniforme. Uma pode apropriar-se continuamente de uma parte do trabalho excedente da outra, pelo qual nada dá em troca, só que nesse caso a medida não é como na troca entre capitalista e trabalhador. (MARX, 2011, p. 747, adendo do editor)

Analisando unicamente o capital industrial ${ }^{6}$, Marx identifica duas formas essenciais de transferência de mais-valor: na concorrência entre capitais em um mesmo ramo; e entre capitais em distintos ramos de produção. Começando pelo segundo caso, o ponto fundamental é a tendência à formação de uma taxa média de lucro, uma vez que os capitais, via de regra e desconsiderando-se as restrições que se lhes interpõem, tendem a migrar para os ramos que oferecem taxas de lucro maiores. Se

\footnotetext{
5 Como esclarece Marx: "só é possível uma análise científica da concorrência depois que se apreende a natureza interna do capital, assim como o movimento aparente dos corpos celestes só pode ser compreendido por quem conhece seu movimento real, apesar de sensorialmente imperceptível" (MARX, 2013, p. 391).

${ }^{6}$ A propósito, uma abstração real: uma vez que não se pode apropriar de algo que não existe, a apropriação de mais-valor por capitais que não o produzem diretamente pressupõe o processo de produção e circulação do mais-valor.
} 
não fosse assim, dadas as diferenças nas composições orgânicas ${ }^{7}$ e nos tempos de rotação que vigoram entre os ramos distintos (para dada taxa de mais-valor), as taxas de lucro nos diferentes ramos seriam profundamente desiguais (MARX, 2008, pp. 202-3).

A concorrência, portanto, iguala as taxas de lucro distintas que vigorariam nos diferentes ramos de produção "numa taxa geral de lucro, que é a média de todas elas" (MARX, 2008, p. 211). Na prática, a tendência à uniformização da taxa de lucro significa que os capitais cobram participação no mais-valor socialmente produzido segundo seu tamanho, não de acordo com o mais-valor gerado nos respectivos ramos de produção. Portanto, os ramos de composições orgânicas superiores apresentam diferenciais positivos entre o preço de produção ${ }^{8}$ e o valor das mercadorias produzidas em cada um deles, o que é compensado pelo desvio negativo, nesse mesmo quesito, nos ramos de composições orgânicas inferiores.

Com relação à transferência do mais-valor no interior de um ramo de produção, uma vez que é a média social, o tempo de trabalho socialmente necessário, que determina o valor de mercado, os capitais mais produtivos (isto é, que produzem em menor tempo e, portanto, cuja mercadoria individual contém menor valor) tendem a apropriar-se de parte do mais-valor produzido pelos capitais menos produtivos. Ou seja, é também a diferença na produtividade do trabalho que determina a transferência de mais-valor em um mesmo ramo de produção. Uma vez que a luta concorrencial se desenvolve, em última instância, "por meio do barateamento das mercadorias" (MARX, 2013, p. 702), cada capital tem estímulos para aplicar métodos mais produtivos. A despeito de que no nível fenomênico as formas da concorrência tenham se tornado profundamente mais complexas ao longo do século XX, especialmente pelo uso de meios de comunicação inexistentes à época de Marx e, por eles, da aplicação de técnicas de "manipulação socialmente consciente das massas" (LUKÁCS, 2012, p. 46), os diferenciais na produtividade do trabalho aplicado nos distintos capitais correspondem à essência das transferências de mais-valor.

Em síntese:

A produtividade particular do trabalho em determinado ramo ou em determinada empresa desse ramo interessa apenas aos

\footnotetext{
7 Composição em valor do capital - relação entre capital constante e capital variável determinada por sua composição técnica - relação entre meios de produção e força de trabalho - , isto é, pela produtividade do trabalho.

$8^{\prime \prime} \mathrm{O}$ preço de produção da mercadoria é (...) igual ao preço de custo mais o lucro que percentualmente se lhe acrescenta correspondente à taxa geral de lucro, ou igual ao preço de custo mais o lucro médio." (MARX, 2008, p. 210) O preço de custo, por sua vez, corresponde à parte produtivamente consumida do capital constante em um determinado período e ao capital variável necessário para mobilizar a força de trabalho necessária.
} 
capitalistas aí diretamente participantes, e na medida em que capacita esse ramo especial em relação ao capital total, ou o capitalista individual em relação a esse ramo, a extrair um lucro extra. (MARX, 2008, p. 256)

Tomando-se rigorosamente o método da Crítica da economia política, toda a sua análise não apenas segue válida ao nível do mercado mundial, como o pressupõe ${ }^{9}$. O mercado mundial é, ao mesmo tempo, o ponto de partida ${ }^{10}$ do modo de produção capitalista e seu resultado continuamente posto ${ }^{11}$ em escala crescente. Em outros termos:

o mercado mundial, a conclusão, em que a produção é posta como totalidade, assim como cada um de seus momentos; na qual, porém, todas as contradições simultaneamente entram em processo. O mercado mundial, portanto, constitui ao mesmo tempo o pressuposto e o portador da totalidade (MARX, 2011, pp. 170-1).

Indo direto ao ponto por meio da pena de Chattopadhyay: "Todos estes processos [de transferência de mais-valor] são postos juntos, em maior complexidade, na concorrência ao nível da economia mundial" (CHATTOPADHYAY, 2012, p. 75, adendo nosso'2). Há transferência de mais-valor intrarramos e inter-ramos de produção no mercado mundial. A maior complexidade do fenômeno, com relação à sua consideração na forma mais simples/ abstrata acima exposta, decorre, inicialmente, do fato de que esses capitais têm por base diferentes nações. Não é sem razão, portanto, que Dussel propõe a categoria "capital global nacional" para proceder à análise das determinantes dos fluxos internacionais de maisvalor, tomando-a, destarte, em termos muito gerais ${ }^{13}$ (DUSSEL, 1988, p. 336).

${ }^{9}$ A seguinte anotação de Marx não dá espaço para mal-entendidos no tocante a isto: "No conceito mais simples do capital, têm de estar contidas em si suas tendências civilizatórias etc.; não podem aparecer, tal qual nas teorias econômicas até aqui, como meras consequências externas. Da mesma forma, é preciso demonstrar que nele já estão latentes as contradições posteriormente liberadas." (MARX, 2011, p. 338)

10 "O comércio e o mercado mundiais inauguram, no século XVI, a história moderna do capital." (MARX, 2013, p. 223)

${ }^{11}$ Como dito nos Grundrisse e facilmente demonstrado a partir da lei do valor de Marx: "O capital, portanto, da mesma maneira que, por um lado, tem a tendência de criar continuamente mais trabalho excedente, tem a tendência complementar, por outro, de criar mais pontos de troca; (...) no fundo de propagar a produção baseada no capital ou o modo de produção que lhe corresponde. A tendência de criar o mercado mundial está imediatamente dada no próprio conceito do capital." (MARX, 2011, p. 332, grifos do autor)

${ }^{12}$ A tradução dos textos em idioma estrangeiro foi feita pelo autor.

13 Cada capital global nacional tem uma composição orgânica que representa "a média total das composições médias de todos os ramos da produção" de um país (MARX, 2013, p. 689). Nesse sentido, a categoria é útil para ajudar a compreender a tendência geral dos fluxos internacionais de mais-valor entre países de desenvolvimento capitalista clássico e não-clássico. Trata-se, evidentemente, de uma abstração que, como tal, é limitada e deve ser dissolvida no curso da análise da concorrência no mercado mundial. 
A síntese dos capitais globais nacionais, diz Dussel, corresponde a um "capital global mundial", no interior do qual a concorrência "internacional cumple su papel de nivelación y distribución de la totalidad del plusvalor mundial” (DUSSEL, 1988, p. 337). Ademais, cada capital global nacional é relativamente autônomo frente ao capital global mundial. Assim, o tema a ser definido inicialmente é o da concorrência entre capitais globais nacionais com graus de produtividade do trabalho mais e menos desenvolvidos.

Como lei geral, "capitais globais nacionais" com maior grau de desenvolvimento das forças produtivas tendem a se apropriar de maisvalor extra, às expensas de “capitais globais nacionais” em pior situação, tanto na interação em um mesmo ramo de produção quanto entre ramos de produção distintos. Isto é, "en el mercado mundial los países con un desarrollo técnico más elevado obtienen ganancias extraordinarias a costas de aquellos países cuyo desarrollo técnico y económico está rezagado" (GROSSMANN, 1979, p. 280). Esse quadro patenteia, tomando-se apenas estas determinações, uma forma de relação internacional na qual algumas nações estão em posição subordinada diante de outras. Em outros termos, certas nações (notadamente aquelas cuja produtividade do trabalho encontra-se menos desenvolvida) estão subalternamente inseridas no mercado mundial.

Dado o escopo de O capital, não pode causar espanto a ausência do tratamento sistemático da dominação internacional na obra. No entanto, quando a aborda, Marx o faz especialmente no âmbito da influência do mercado mundial sobre a taxa de lucro. Na breve nota sobre o comércio exterior como tendência contrarrestante à queda da taxa de lucro, a questão de fundo é precisamente a transferência do mais-valor. No trecho, é considerado o efeito do comércio exterior sobre o valor do capital constante e do capital variável no país com forças produtivas mais desenvolvidas, a concorrência entre capitais de um mesmo ramo e a aplicação direta de capital nas "colônias". Em síntese, quanto maior a transferência de mais-valor para o país de capital global nacional com maior composição orgânica, maior a força contrária à queda da taxa de lucro no país.

No intercâmbio, o país favorecido recebe mais trabalho do que dá, embora essa diferença, esse mais, como ocorre no intercâmbio entre trabalho e capital, embolse-o determinada classe. A taxa de lucro mais alta, por ser mais alta no país colonial, pode coincidir, havendo nele condições naturais favoráveis, com mercadorias de preço baixos. (MARX, 2008, p. 314)

A tendência à transferência de mais-valor na direção dos capitais globais nacionais mais produtivos, que se reflete, como adianta Marx em O 
capital, nos ajustes das balanças internacionais de comércio (MARX, 2013, p. 217), implica uma propensão ao endividamento dos estados que baseiam capitais globais nacionais menos produtivos. (Ainda que não tenhamos a intenção de desenvolver este ponto neste artigo, note-se que os fluxos internacionais de dinheiro refletem as transferências globais do mais-valor.) Passemos imediatamente à discussão sobre a forma como Marx compreendia o dinheiro para, em seguida, analisarmos sua metamorfose histórica mais recente e suas implicações.

\section{Dinheiro e dinheiro mundial em Marx}

“O processo de troca”"14 diz respeito, precisamente, às relações entre possuidores de mercadorias. A síntese das relações mercantis se apresenta como "mercado", que tem no dinheiro sua figura acabada. Não é demais recordar que o mercado pressupõe uma forma historicamente específica do produto (a mercadoria), cuja dupla natureza (valor de uso e valor) representa a contradição fundamental da sociabilidade burguesa (entre o caráter privado e o caráter social da riqueza), a partir da qual podemos alcançar as determinações mais complexas desta forma de existência.

A circulação dos produtos do trabalho nessa forma histórica, reconhece Marx, depende de um determinado arcabouço jurídicoinstitucional que possibilite "um ambiente de trocas, uma totalidade de trocas em contínuo fluxo e operando mais ou menos em toda a superfície da sociedade; um sistema de atos de trocas", não apenas "atos de troca singulares" (MARX, 2011, p. 135). Na sociabilidade mercantil, ademais, os papéis de cada um dos indivíduos engajados no processo "não passam de personificações das relações econômicas” (MARX, 2013, p. 160). A força motriz que aciona o comportamento de cada um diz respeito a suas necessidades privadas. No entanto, esse ímpeto privado realiza-se, ou não, no mercado, no "processo social geral" da troca. Assim, "não é possível que, simultaneamente para todos os possuidores de mercadorias, o mesmo processo seja exclusivamente individual e, ao mesmo tempo, exclusivamente social geral"' (MARX, 2013, p. 161).

Podemos, dessa forma, aproximar-nos de uma primeira definição de mercado, sem, todavia, transcendermos o nível de abstração da circulação simples: a articulação social dos sujeitos que trocam. Ou ainda: "A dependência multilateral dos indivíduos mutuamente indiferentes", por meio do valor (MARX, 2011, p. 105). Notemos que, embora as ações individuais obedeçam a posições teleológicas, seu resultado social, que depende da complexa articulação das inúmeras ações privadas, é incontrolável para cada um dos sujeitos.

14 Título do segundo capítulo do Livro I de O capital. 
Na medida em que, ademais, a articulação pela troca está subsumida às necessidades do capital, a relação do valor é, nas palavras de Marx, "apenas uma relação social determinada entre os próprios homens que aqui assume, para eles, a forma fantasmagórica de uma relação entre coisas" (MARX, 2013, p. 147). Dito de outro modo, as relações mercantis constituem um fetiche porque sua dinâmica, além de incontrolável pelos sujeitos, está subordinada a imperativos alheios: o movimento da acumulação de capital, apreendido teoricamente na lei do valor. Nas palavras de Marx, o entrechoque dos sujeitos na troca "produz um poder social que lhes é estranho, que está acima deles; sua própria interação [aparece] como processo e poder independentes deles" (MARX, 2011, p. 144, grifo do autor, adendo do editor).

Note-se que esse processo social põe o dinheiro, pois, para que todos se relacionem com todos no intercâmbio mercantil, todos os componentes do produto social devem ser comparáveis entre si, o que só se pode realizar por meio de um único objeto que possua as mesmas determinações sociais (trabalho abstrato, isto é, valor). Esta mercadoria é o dinheiro, quer contenha essa determinação social diretamente (por exemplo, o ouro) ou indiretamente (como na forma inconversível da moeda). A sociabilidade mercantil demanda uma forma externa de expressão da contradição interna à mercadoria (valor e valor de uso), o que põe o dinheiro como figura independente do valor.

O dinheiro, portanto, é o representante da riqueza universal. Por isso, aparece para os indivíduos inseridos na dinâmica mercantil como valor em si, independentemente das relações entre os seres humanos, da relação do valor. Isto é, o dinheiro expressa, em sua figura acabada (sem referência imediata ao processo de sua gênese), a conexão social pela troca ${ }^{15}$. "O dinheiro, por isso, é o deus entre as mercadorias." (MARX, 2011, p. 165) Tudo o que é produzido tem de ser riqueza universal (valor), o que só se pode comprovar socialmente no intercâmbio pelo dinheiro.

A circulação desenvolvida das mercadorias representa a ruptura com "as barreiras individuais e locais da troca direta de produtos" (MARX, 2013, p. 186), o que acha expressão no contínuo fluxo do dinheiro. A consolidação do mercado na figura acabada do dinheiro parte, tanto em termos lógico-categoriais como ontológicos, da função de medir os valores das diversas mercadorias - isto é, pelo fato das mencadorias expressarem no dinheiro seu valor. Na análise da forma valor, no primeiro capítulo de O

15 Como dito por Marx: "Decorre daí a magia do dinheiro. O comportamento meramente atomístico dos homens em seu processo social de produção e, com isso, a figura reificada [sachliche] de suas relações de produção, independentes de seu controle e de sua ação individual consciente, manifestam-se, de início, no fato de que os produtos de seu trabalho assumem universalmente a forma mercadoria. Portanto, o enigma do fetiche do dinheiro não é mais do que o enigma do fetiche da mercadoria que agora se torna visível e ofusca a visão." (MARX, 2013, p. 167) 
capital, Marx demonstra como a determinação valor de uma mercadoria, na medida em que não aparece de imediato em sua forma material, pode apenas se manifestar como valor de troca no corpo de outra mercadoria, que na relação assume o papel de equivalente. O preço é, portanto, a tradução do valor da mercadoria em dinheiro (MARX, 2011, p. 135).

No entanto, "a mercadoria não é preço" (MARX, 2011, p. 137, grifos do autor). O preço como forma necessária de manifestação do valor não implica, necessariamente, a conversão de mercadoria em dinheiro. Isto é, o preço representa a possibilidade da realização do valor, não sua efetividade. Como diz Marx, o ouro pode medir o valor das mercadorias porque, assim como elas, contém tempo de trabalho socialmente necessário, mas para cumprir esta função não é necessário que apareça de antemão um único grama do metal (MARX, 2013, p. 171). A forma-preço indica a "necessidade" da venda (MARX, 2013,p. 178). Nesta, a mercadoria é convertida em dinheiro, realizando seu preço, isto é, seu valor. Ou seja, a forma mercadoria encerra uma contradição que opõe mercadoria e dinheiro; essa contradição é solucionada (mas não superada) na metamorfose da mercadoria, seu movimento. "Esse é, em geral, o método com que se solucionam contradições reais" (MARX, 2013, p. 178).

Na realização do valor (pelo preço), o dinheiro funciona como meio de compra. Tendo em vista a totalidade do metabolismo social mercantil, o dinheiro cumpre a função de meio de circulação. Nesta função, o dinheiro tem de interpor-se entre uma mercadoria e outra (M-D-M) para que um produtor tenha a possibilidade de passar de vendedor a comprador de mercadoria(s). Ou seja, para mediar a circulação das mercadorias, o dinheiro deve apenas mudar continuamente de mãos. Por isso:

Na medida em que ele [o dinheiro] realiza o preço, sua existência material como ouro e prata é essencial; mas na medida em que essa realização é apenas fugaz e deve suprimir a si mesma, essa existência material é indiferente. É somente uma aparência, como se se tratasse de trocar a mercadoria por ouro ou prata como uma mercadoria particular; uma aparência que desvanece quando o processo está concluído, tão logo o ouro ea prata são de novo trocados por mercadoria e, com isso, mercadoria é trocada por mercadoria. Por essa razão, o ouro e a prata como simples meio de circulação, ou o meio de circulação como ouro e prata, é indiferente com respeito a sua qualidade como uma mercadoria natural e particular. (MARX, 2011, p. 155, grifos do autor, adendo nosso)

Reside aí a possibilidade da transformação do dinheiro em moeda, para cumprir a função meio de circulação, isto é, a substituição do dinheiro por "outro signo" (MARX, 2011, p. 158, grifo do autor). Ademais, Marx explica em $\mathrm{O}$ capital como determinadas contingências históricas transformaram essa possibilidade em realidade (MARX, 2013, pp. 198-9): 
Coisas relativamente sem valor, como notas de papel, podem, portanto, funcionar como moeda em seu lugar. Nas senhas metálicas, o caráter puramente simbólico ainda se encontra de certo modo escondido. Como se vê, ce n'est que le premier pas que coûte [difícil é apenas o primeiro passo]. (MARX, 2013, p. 200, adendo do editor)

A representação do dinheiro em moeda é atribuição do estado, que estabelece e garante (ao menos idealmente) a sua conversibilidade (MARX, 2013, pp. 202-3). Nas diversas moedas, o dinheiro (ouro e prata) "[veste] uniformes nacionais (...) dos quais [volta] a se despojar no mercado mundial", o que manifesta "a separação entre as esferas internas ou nacionais da circulação das mercadorias", nas quais circulam obrigatoriamente as moedas nacionais, "e a esfera universal do mercado mundial" (MARX, 2013, p. 198). Da relação entre moeda e dinheiro, contudo, deriva-se a limitação do poder do estado no que diz respeito à circulação monetária: a lei segundo a qual "a emissão de papel-moeda deve ser limitada à quantidade de ouro (ou prata) - simbolicamente representada pelas cédulas - que teria efetivamente de circular" (MARX, 2013, p. 201).

Para cumprir os objetivos da presente seção, devemos agora seguir às funções nas quais o dinheiro deve aparecer como dinheiro. Isto é, "quando, em virtude de sua função, seja ela realizada em sua própria pessoa ou por um representante, ele se fixa exclusivamente na figura de valor, a única forma adequada de existência do valor de troca" (MARX, 2013, p. 203). Esta, que nos Grundrisse Marx chama de "terceira determinação do dinheiro", "pressupõe as duas primeiras determinações e é a sua unidade" (MARX, 2011, p. 161, grifos do autor). Se o dinheiro (qualquer que seja sua forma) é capaz de cumprir as duas primeiras determinações (medir universalmente valores e mediar a circulação das mercadorias), pode funcionar em sua terceira.

Uma vez que o dinheiro representa a autonomização do valor com relação à circulação (MARX, 2013, p. 162) e que nele o "conceito de riqueza está, por assim dizer, realizado, individualizado, em um objeto particular" (MARX, 2013, p. 164), ele é o meio adequado para a reserva de valor. Isto a despeito da variabilidade de seu valor de troca. Dado seu caráter qualitativamente infinito: "Todas as mercadorias são somente dinheiro perecível; o dinheiro é a mercadoria imperecível” (MARX, 2013, p. 174). Este aspecto, como tudo o que se disse sobre o valor, aparece de maneira plena apenas quando se considera, explicitamente, a transformação do dinheiro em capital. É por isso que, ao nível de abstração da circulação simples, o "entesouramento" soa como uma paixão irracional, típica de sociedades pré-capitalistas. A função social do entesouramento, para além da circulação simples das mercadorias, é considerada por Marx no escopo 
da análise sobre a reprodução do capital ${ }^{16}$; e o meio adequado para a manutenção dessas reservas só aparece na análise da "autonomização das formas funcionais do capital”17, com o capital bancário.

Ademais, dinheiro em espécie também é cobrado para saldar compromissos previamente estabelecidos. Neste caso, sua função é servir como meio de pagamento, cuja necessidade pode ser vislumbrada já na análise da circulação simples, uma vez que os diferentes tempos requeridos para a produção de distintas mercadorias põem as "condições por meio das quais a alienação da mercadoria é temporariamente apartada da realização de seu preço" (MARX, 2013, p. 208). Em termos lógicocategoriais e históricos, é desta função que se origina o "dinheiro creditício", "quando certificados de dívida relativos às mercadorias vendidas circulam a fim de transferir essas dívidas para outrem" (MARX, 2013, p. 213).

Em suma, o dinheiro transparece nessas relações como "material universal dos contratos", sendo considerado, portanto, "mercadoria universal, representante da riqueza universal (...), valor de troca ${ }^{18}$ autonomizado" (MARX, 2011, p. 179, grifos do autor). O mesmo ocorre na circulação da riqueza no mercado mundial, com o dinheiro mundial. Como dito acima, no mercado mundial o dinheiro deve se despir de seus uniformes nacionais, isto é, "o dinheiro em sua terceira determinação como dinheiro autonomamente saído da (e contraposto à) circulação, nega ainda seu caráter como moeda" (MARX, 2011, p. 169, grifo do autor). Isso acontece porque, para expressar de maneira verdadeiramente universal (i.e. no mercado mundial) a sociabilidade mercantil, é necessária uma forma única (no nível mundial) de manifestação do valor. A "mercadoria universal que conserva em todos os lugares o seu caráter de mercadoria", portanto, de portadora de valor, em "virtude dessa determinação formal, vale uniformemente em todos os lugares. Somente assim é o representante material da riqueza universal" (MARX, 2011, pp. 169-70, grifo do autor).

A forma plena em que o dinheiro aparece como corporificação do trabalho humano abstrato no mercado mundial (MARX, 2013, p. 215),

\footnotetext{
${ }^{16}$ A partir da Seção VII do Livro I de O capital. Como nota Saad Filho: “(...) existem razões estruturais para a formação de reservas durante a produção capitalista. A razão mais importante é que a produção envolve despesas regulares que são geralmente desconectadas do recebimento das receitas de vendas. Os produtores precisam também acumular reservas para realizar despesas inesperadas, manter e repor o capital fixo, aumentar a produção, pagar dividendos, contrapor-se a flutuações de preços, e assim por diante" (SAAD FILHO, 2011, p. 155).

${ }^{17}$ Nas Seções IV e V do Livro III de O capital.

18Vale apontar que é exatamente ao longo da redação dos Grundrisse que Marx chega a algumas mediações categoriais fundamentais para sua Crítica da economia política, dentre as quais a diferença entre valor e valor de troca. Desta forma, nos trechos iniciais da obra (como o que citamos) o autor emprega as categorias indistintamente. Sobre isso ver Rosdolsky (2001, p. 506).
} 
como dinheiro mundial, representa a síntese dialética de todas as funções do dinheiro: "O dinheiro mundial funciona como meio universal de pagamento, meio universal de compra e materialidade social da riqueza universal [universal wealth]" (MARX, 2013, p. 217). Ou seja, como analisa Rosdolsky, "no mercado mundial, o dinheiro não recebe funções especiais diferentes das que já conhecemos", mas aparece na universalidade adequada ao seu conceito (ROSDOLSKY, 2001, p. 144).

Marx ressalta, no entanto, que o dinheiro serve como meio de compra internacional apenas em ocasiões excepcionais. "O que predomina é sua função como meio de pagamento para o ajuste das balanças internacionais." (MARX, 2013, p. 217) Assim, o dinheiro aparece como "saldo do excedente no processo global da troca internacional de mercadorias" (MARX, 2011, p. 170) e seu fluxo, portanto, como forma de transferência de riqueza de um país a outro ${ }^{19}$, como reflexo do movimento internacional do valor.

\section{A forma contemporânea do dinheiro}

A análise das transformações históricas que puseram a forma contemporânea do dinheiro pressupõe a demonstração, retrospectiva, das condições que impuseram o abandono do padrão dólar-ouro. Nesse caso, deve-se notar de saída que é precisamente no exame do dinheiro-capital ${ }^{20}$ que a existência metálica do dinheiro patenteia-se barreira para o processo de acumulação do capital nesta forma e, portanto, para a acumulação de capital em geral (dada a inextricável conexão entre as diferentes espécies de capital21), na medida em que a base metálica corresponde ao limite último para a expansão do crédito e, desse modo, para a criação de títulos negociáveis derivados das operações creditícias iniciais (ou seja, capital

\footnotetext{
${ }^{19}$ Além da riqueza que se transfere por essa via, Marx considera, na mesma Seção I do primeiro livro de $\mathrm{O}$ capital, a "transferência de riqueza de um país a outro (...) nos casos em que essa transferência na forma das mercadorias é impossibilitada, seja pela conjuntura o mercado, seja pelo próprio objetivo que se busca realizar" (MARX, 2013, pp. 217-8). Por exemplo, "para subsídios, empréstimos em dinheiro para a realização de guerras ou para permitir aos bancos a cobertura de pagamentos em dinheiro etc., é precisamente a forma-dinheiro que é requerida como valor" (MARX, 2013, p. 218).

20 Referimo-nos às espécies de capital derivadas (apenas em termos lógico-categoriais) das funções exercidas pelo capital-dinheiro no ciclo de acumulação do capital em geral. A análise do ciclo do capital em geral, do ponto de vista do capital-dinheiro, é realizada por Marx no primeiro capítulo do Livro II de O capital (MARX, 2014, pp. 107-41); e a análise do dinheiro como forma autônoma de capital (capital de comércio de dinheiro, capital portador de juros - sintetizados dialeticamente no capital bancário - e capital fictício) é objeto das Seções IV e V do Livro III da mesma obra (MARX, 2008, pp. 357-809).

21 Cujos determinantes e implicações não teremos a ocasião de abordar neste texto. A esse respeito, ver Carcanholo (2010, p. 6); e Painceira e Carcanholo (2009, pp. 5-11).
} 
fictício) ${ }^{22}$. Nas palavras de Marx, o dinheiro na forma metálica "constitui o fulcro de que nunca se pode desprender, pela própria natureza, o sistema de crédito" (MARX, 2008, p. 802).

Não obstante, para o capital, cada "limite aparece como barreira a ser superada” (MARX, 2011, p. 332). Assim, a necessidade do alargamento do valor colide com todas as barreiras que se lhe antepõem (erguidas em seu próprio movimento, isto é, como resultado de suas contradições internas), o que aponta para a necessidade de sua transposição. No caso específico que estamos analisando, Marx pôde observar em seu tempo que: com o desenvolvimento do sistema de crédito, a produção capitalista sem cessar empenha-se em suprimir essa barreira metálica, esse limite, sincronicamente material e fantástico, à riqueza e ao movimento dela, mas acaba sempre quebrando a cabeça contra esse obstáculo (MARX, 2008, p. 761).

O ulterior desenvolvimento do modo de produção capitalista, contudo, fez emergir, finalmente, a necessidade histórica da ultrapassagem deste obstáculo. No final da década de 1960, o período de expansão do processo de acumulação de capital iniciado no pós-guerra dá mostras de seu esgotamento em uma crise que atravessou os anos 1970 e assumiu, fundamentalmente, duas formas: quedas nas taxas de lucro e superacumulação de capital (CARCANHOLO, 2010, p. 2). Nesse contexto, o processo de acumulação de capital começa, já nos anos 1970, a apontar os elementos que vão permitir a sua posterior retomada.

De fato, o capitalismo mundial passou por profundas transformações estruturais a partir da referida década, incluindo a completa reorganização e expansão de sua esfera financeira, estimulada pelo abandono do padrão dólar-ouro (PRADO; PINTO, 2011, p. 11). Nas palavras de Paulani, nessas condições:

o dinheiro mundial finalmente se libertou das amarras que lhe impunham sua vinculação a uma mercadoria de verdade. A

\footnotetext{
${ }^{22}$ No estudo sobre os componentes do capital bancário, Marx oferece uma boa ilustração sobre como as reservas de ouro (em poder dos bancos centrais) limitam a expansão do crédito: "Os fundos de reserva, portanto, finalmente se reduzem, na realidade, ao fundo de reserva do Banco da Inglaterra. Mas também este fundo tem, por sua vez, dupla existência. O fundo de reserva do departamento bancário é igual ao excesso dos bilhetes que o Banco pode legalmente emitir sobre os bilhetes que estão circulando. O máximo legal para a emissão de bilhetes é de 14 milhões (que dispensam reserva metálica; [...]) mais o montante do estoque de metais preciosos do Banco. Se esse estoque é de 14 milhões de libras esterlinas, poderá o Banco emitir em bilhetes 28 milhões, e se destes circulam 20 milhões, o fundo de reserva do Banco é de 8 milhões. Esses 8 milhões de bilhetes são, portanto, legalmente o capital do banqueiro à disposição do Banco e, ao mesmo tempo, o fundo de reserva para os próprios depósitos. Se houver exportação de ouro, diminuindo o estoque metálico de 6 milhões - o que acarreta destruição de bilhetes por igual montante - , a reserva do departamento bancário cairá de oito para 2 milhões. $\mathrm{O}$ Banco elevará então consideravelmente a taxa de juros; os bancos que nele depositam e os outros depositantes verão o fundo de reserva diminuir em relação aos saldos que nele possuem" (MARX, 2008, p. 626).
} 
ausência de constrangimentos materiais em relação ao objeto que produz a unidade na qual se conta a riqueza evidentemente vem facilitando o exercício da autonomia que o capital ganha ao se libertar de si mesmo (PAULANI, 2009, p. 30).

Deve-se ressaltar, como bem faz a autora citada, que essa "ausência de constrangimentos materiais", essa "autonomia que o capital ganha" etc. não pode ser senão relativa. Isto é, "do fato de que o capital põe todo limite desse gênero como barreira e, em consequência, a supere idealmente, não se segue de maneira nenhuma que a superou realmente" (MARX, 2011, p. 334). Se a expansão do capital fictício representou um dos momentos fundamentais para a saída da crise dos anos $1970^{23}$, com uma pungente retomada da expansão do capital, de forma alguma foram superadas em definitivo as contradições que a engendraram. Assim tem de ser em um modo de produção que "se move em contradições que constantemente têm de ser superadas, mas que são também constantemente postas" (MARX, 2011, p. 334), ao que podemos adicionar: em maior grau de desenvolvimento, isto é, complexidade ${ }^{24}$.

Sinteticamente, o abandono do padrão metálico permitiu maior autonomia para o valor, na medida em que aprofundou sua ilusão de poder se apropriar de uma riqueza não produzida. A unidade necessária entre valor e valor de uso (ou apropriação e produção), que se escamoteia por trás do vertiginoso crescimento da riqueza fictícia, é, contudo, cobrada justamente nas crises. Não sem razão, portanto, desde a segunda metade da década de 1990, a economia mundial experimenta turbulências, com estopim nas finanças e de periodicidade cada vez mais curta, até precipitar, em 2007, a crise que desde então se desenvolveu em fases distintas, mas cujo fim não se anuncia ${ }^{25}$.

23 Para Carcanholo, as respostas à crise dos anos 1970 perpassam toda a década de 1980, atingindo seu ápice no decênio seguinte. Desta forma: "Neoliberalismo, expansão do capital fictício, transferência do excedente produzido na periferia para o centro (em especial para os Estados Unidos), são as marcas da década de 90 que se mantêm neste início de século." (CARCANHOLO, 2010, p. 3)

24 Como argumentam Duayer e Medeiros: "Analisando, portanto, as estruturas da sociedade do capital, Marx descobre esta dinâmica objetiva, cuja lógica imanente não se dissolve por si mesma, não se autossupera. Pelo contrário, ela arrasta suas contradições para adiante, sempre em grau mais elevado." (DUAYER; MEDEIROS, 2015, p. 21)

25 Segundo Paulani: "A crescente riqueza financeira, que há muito vem se deslocando de ativo para ativo financeiro buscando a valorização que não encontra no mundo da produção real, saiu dos créditos contra as economia latino-americanas para as moedas dos países 'emergentes', daí para as ações das empresas 'pontocom', e finalmente para o mercado imobiliário norte-americano, que, em todos esses passos, teve seus movimentos amplificados pelos derivativos e pela engenharia financeira produzida pela aparentemente completa autonomia do capital. A crise de enormes proporções que ora assistimos não é nada mais do que a revelação da profundidade da contradição envolvida nesses movimentos, os quais vêm embalando o capitalismo há pelo menos três décadas." (PAULANI, 2009, p. 31) Após a redação do texto citado, sobreveio uma nova fase da crise atual: a crise da dívida de estados europeus cujos bancos estavam abarrotados de ativos fictícios "podres" e, portanto, tiveram de ser socorridos. 


\section{Dinheiro desmaterializado, lei do valor e mercado mundial}

O que nos toca, por fim, é analisar em que medida o dinheiro desmaterializado pode exercer suas funções e, portanto, representar valor, apesar de ser desprezível o trabalho nele corporificado. Na verdade, não é por conter tempo de trabalho socialmente necessário ${ }^{26}$ que ele pode desempenhar as funções normais do dinheiro na sociabilidade mercantil, mas porque sua conversibilidade em riqueza real (na forma de mercadorias) está garantida pelo estado emissor. Assim, se a forma monetária do dinheiro, como visto acima, já denotava o poder político, por meio do estado, como um determinante fundamental de seu curso como meio de compra na circulação interna das mercadorias, a liberdade com relação ao padrão aurífero, sem sombra de dúvidas, acentuou enormemente esta dimensão, como veremos a seguir.

Já demonstramos, seguindo Marx, que na função meio de circulação a forma material do dinheiro é indiferente, uma vez que o desenvolvimento das trocas põe a necessidade de o meio de compra não conter, ele próprio, valor. Desta forma, todo o peso do argumento contra a relevância da teoria do valor de Marx diante destas transformações históricas cai sobre a função de medir valores (já que as funções relativas ao "dinheiro como dinheiro", como vimos, estão predicadas à capacidade de exercício dessas duas primeiras determinações). Recordemos que, apesar de sua existência meramente ideal como medida do valor, estampada no preço das mercadorias, o dinheiro pode cumprir esta função, segundo Marx, porque ele mesmo contém trabalho abstrato, isto é, porque ele é uma mercadoria, equiparável a qualquer outra ${ }^{27}$.

A pergunta candente, portanto, é se o dinheiro precisa conter a substância social "valor" para medir valores. De maneira muito perspicaz, Arthur demonstra, inicialmente, como objetos físicos podem servir de medida para outros objetos sem conter necessariamente as propriedades

\footnotetext{
${ }^{26}$ Apesar de ser produzida com meios de produção e força de trabalho adquiridos no mercado, a moeda inconversível propriamente dita não tem diretamente valor. No entanto, sua validade social depende da referência indireta ao valor, pela dívida pública, que representa a promessa de pagamentos futuros, isto é, direitos sobre a apropriação de um valor a ser produzido no futuro. A fragilidade sistêmica deste esquema patenteia-se nas perturbações advindas da descrença quanto à capacidade da produção interna (a uma nação) de valor, vis-à-vis os compromissos com pagamentos futuros assumidos pelo estado.

${ }^{27}$ Nas palavras de Marx: "O ouro só se confronta com outras mercadorias como dinheiro porque já se confrontava com elas anteriormente, como mercadoria. Igual a todas as outras mercadorias, ele também funcionou como equivalente (...). Com o tempo ele passou a funcionar, em círculos mais estreitos ou mais amplos, como equivalente universal. Tão logo conquistou o monopólio dessa posição na expressão de valor do mundo das mercadorias, ele tornou-se mercadoria-dinheiro." (MARX, 2013, p. 145)
} 
medidas, expressando-as indiretamente, o que pressupõe uma teoria que permita a compreensão da relação entre o que se quer medir e a outra entidade comensurável contida no objeto medidor ${ }^{28}$ (ARTHUR, 2005, pp. 115-16). No caso de objetividades puramente sociais, como o valor, são as inúmeras práticas dos indivíduos imersos nas relações sociais de produção burguesas que põem, continuamente, a dimensão homogênea a ser medida (o valor) e a necessidade da comensurabilidade universal. Assim, basta que essas diversas práticas individuais validem o dinheiro como medida do valor, qualquer que seja a sua forma, nas relações mercantis. Nas palavras de Arthur:

\begin{abstract}
Apenas pela mediação do dinheiro podem outras tais dimensões sociais das mercadorias como sua representação de trabalho abstrato socialmente necessário ser assegurada. Vimos que medida indireta é possível se há uma relação entre o que queremos medir e alguma outra entidade comensurável; conquanto a prática social atue para fazer do dinheiro-papel uma função do determinante valor, tal medida é adequada aos valores relativos das mercadorias, assim como uma balança de molas [spring balance] mede peso ainda que molas não sejam pesadas. Se estamos olhando para alguma coisa medindo valor definido como poder de troca, então alguma coisa que é apenas isso, nominalmente, que tem trocabilidade [exchangeability], é uma forma perfeita de medida; e se dinheiro fiduciánio possui tal aceitação social, então é uma medida adequada, a despeito do fato de que ele mesmo não contém trabalho. Conquanto tal dinheiro valide mercadorias e, portanto, trabalho, que outra medida é requerida? (ARTHUR, 2005, p. 117, grifo do autor, adendos nossos)
\end{abstract}

A forma contemporânea do dinheiro põe, portanto, a questão da crença dos indivíduos na capacidade de o estado garantir sua conversibilidade em mercadorias de modo ainda mais acentuado que no caso do padrão-metálico. Se a relação da moeda inconversível com o valor é abalada (independentemente de qual seja a raiz concreta deste abalo), podem advir perturbações monetárias (como um processo inflacionário, por exemplo) ou mesmo o completo colapso da moeda (como em uma hiperinflação). De todo modo, se a moeda inconversível em metal pode medir valor e mediar a circulação das mercadorias, ela é o meio adequado para reserva de valor, para saldar compromissos e para fazer circular as mercadorias mundialmente. Embora, neste último caso, a forma única de manifestação do valor em nível mundial seja ainda necessária e, portanto,

28 É o caso, por exemplo, de um termômetro de mercúrio, cuja extensão mede a força e a vibração das moléculas. O termômetro pode medir o calor porque há uma teoria sobre sua determinação que permite traduzir o calor, "de trás para frente", em sua escala (ARTHUR, 2005, p. 115). 
apresente-se em maior complexidade, em termos geopolíticos, a questão do poder do estado emissor da moeda universal.

Podemos nos acercar desta questão por meio das seguintes considerações de Lapavitsas sobre a forma como Marx entende o dinheiro mundial:

\begin{abstract}
Primeiro, dinheiro mundial possui o atributo fundamental de todo "dinheiro como dinheiro": manter-se à parte do domínio regular da circulação capitalista, permanecendo, no entanto, capaz de intervir decisivamente na transferência de valor ou ajuste de balanços. Segundo, e relacionado ao primeiro, os agentes que operam no mercado mundial são obrigados a portar dinheiro mundial para poder agir no mercado nos momentos devidos. Há um elemento de compulsão externa no portar dinheiro mundial, e não mera decisão. Terceiro, portanto, portar dinheiro mundial é um instrumento de poder para participantes do mercado mundial. Sua posse oferece a oportunidade de se pagar e transferir valor em momentos críticos, moldando, assim, os processos subjacentes de criação e circulação de valor. Quarto, compulsão e poder conjuntamente reafirmam o fundamental "caráter de dinheiro" do dinheiro mundial, qual seja, sua habilidade de comandar mercadorias e de emergir como a forma absoluta do valor no mercado mundial. (LAPAVITSAS, 2013, p. 98)
\end{abstract}

Assim, mesmo no caso da moeda conversível em ouro como padrão para o comércio internacional (como no padrão dólar-ouro), o poder da nação emissora é colossal, na medida em que a disposição de reservas ${ }^{29}$ representa enorme vantagem em um mercado mundial que continuamente demanda ajustes em balanços de pagamentos (sobremaneira violentos em momentos de crise), assim como (também por isso) facilita o exercício de poder político e militar globalmente (LAPAVITSAS, 2013, p. 99). Foi precisamente o estalar da crise e o acirramento na disputa internacional por mais-valor ${ }^{30}$ que precipitou a perda de reservas metálicas dos Estados Unidos, forçando o cancelamento da conversibilidade do dólar em 1971 (KURZ, 2014, pp. 190-1).

A despeito disso, na ausência de alternativa viável, o dólar pôde manter seu posto de dinheiro mundial, desde então livre do pesado fardo metálico, mas crescentemente dependente do poder político dos Estados Unidos. De maneira peculiar, como aponta Kurz, a necessidade da

${ }^{29}$ Segundo Kurz, o estabelecimento do padrão dólar-ouro em Bretton Woods teve por base não apenas "a primordial posição industrial dos Estados Unidos (devido em grande parte à tremenda arrancada de crescimento da economia de guerra), mas também o fato de que o dólar era a única moeda conversível em ouro. $\mathrm{O}$ famoso Forte Knox retinha três quartos das reservas mundiais de ouro" (KURZ, 2014, p. 190).

30 Para Montoro, o dólar sobrevalorizado, como consequência do padrão dólar-ouro, "a principios de los 60, cuando Japón y algunas economías europeas comienzan a ser competitivas", passa a ser desvantajoso para os Estados Unidos, "porque le mermará competitividad al encarecer sus exportaciones" (MONTORO, 2014, p. 289). 
afirmação de um poder global em uma conjuntura de perda de espaço no mercado mundial deu lugar a "um crescimento contínuo do que o presidente Eisenhower descrevera como 'complexo militar-industrial'" (KURZ, 2014, p. 192).

Essa espécie de "keynesianismo armado", por um lado, converteu-se em poderosa alavanca de crescimento econômico e, por outro, garantiu flancos para avanço do capital estadunidense. Ademais, sem pretender explorar exaustivamente esta questão, note-se ainda que a transformação do dólar em dinheiro mundial, que possibilitou o supracitado aprofundamento da autonomia (sempre relativa) do valor pelo crescimento da riqueza fictícia, garantiu a transferência de mais-valor produzido globalmente para os Estados Unidos, inclusive pela via financeira. Nas palavras de Lapavitsas: "O dinheiro mundial tornou-se ainda mais claramente um instrumento de poder de estado, particularmente de poder hierárquico, imperial, no mercado mundial." (LAPAVITSAS, 2013, p. 100)

Em suma, as condições de valorização do valor no mercado mundial transformaram-se profundamente nas últimas décadas, o que não pode deixar de ser considerado de maneira extremamente cuidadosa por qualquer análise séria desta realidade. Argumentamos aqui pela importância da teoria do valor de Marx para compreender estas transformações, tendo em vista a nova forma do dinheiro mundial como síntese da nova configuração do mercado mundial. Nas palavras de Montoro:

las cuestiones monetarias son muy importantes en una economía de mercado como es la capitalista, porque es a través de ellas cómo finalmente se verifica el proceso económico completo, que ha de incluir el intercambio; es decir, la validación social de los trabajos privados. Por ello, las cuestiones monetarias no son autónomas de la ley del valor sino, al contrario, un elemento integrante de cómo se materializa ésta. Cuando ya no se trata del plano nacional, sino de las relaciones internacionales, las cuestiones monetarias son además (...) un elemento más, pero muy importante, de la pugna interimperialista, de las desiguales relaciones que se establecen entre las diferentes burguesías nacionales a través de sus respectivos estados (MONTORO, 2014, p. 283).

Pelo dinheiro confirma-se, ou não, portanto, a validade social do trabalho despendido na produção de mercadorias, inclusive no nível mundial. Por meio dele, consumam-se as transferências internacionais de mais-valor e cristaliza-se a desigualdade no desenvolvimento capitalista global, isto é, a operação necessariamente desigual da lei do valor no mercado mundial. Como dito por Marx nos Grundrisse: "O que importa aqui - onde é considerado o conceito geral do capital - é que ele não é essa 
unidade de produção e valorização de maneira imediata, mas só como um processo ligado a condições que, como vimos, são condições externas." (MARX, 2011, p. 331, grifos) Em suma, apontamos neste artigo, ainda que marginalmente, para algumas dessas condições externas em âmbito mundial, em um contexto histórico específico. Acreditamos que tais condições possam servir de base para a descrição científica dos mecanismos subjacentes às formas contemporâneas de transferência de mais-valor, em especial, o aumento da importância relativa de suas facetas financeiras.

\section{Referências bibliográficas}

ARTHUR, C. "Value and money". In: MOSELEY, F. Marx's theory of money: modern appraisals. Nova York: Palgrave Macmillan, 2005.

CARCANHOLO, M. A crise econômica atual e seus impactos para a organização da classe trabalhadora. Aurora, Marília, ano IV, n. 6, ago. 2010.

CHATTOPADHYAY, P. “Competition”. In: FINE, B.; SAAD-FILHO, A. The Elgar companion to Marxist economics. Cheltenham: Edward Elgar, 2012. DUAYER, M.; MEDEIROS, J. L. "Marx, estranhamento e emancipação: o caráter subordinado da categoria da exploração na análise marxiana da sociedade do capital". In: MIRANDA, F.; MONFARDINI, R. Coleção NiepMarx v. II: ontologia e estética. Rio de J aneiro: Consequência, 2015.

DUSSEL, H. Hacia un Marx desconocido. Un comentario de los Manuscritos del 61-63. Iztapalapa: Siglo XXI, 1988.

GROSSMANN, H. La ley de la acumulación y del derrumbe del sistema capitalista. México: Siglo XXI Editores, 1979.

KURZ, R. "World power and world money: the economic function of the US Military machine within global capitalism and the background of the new financial crisis". In: LARSEN, N. et al. Marxism and the critique of value. Chicago: MCM' Publishing, 2014.

LAPAVITSAS, C. Profit without producing: how finance exploits us all. Londres: Verso, 2013.

LUKÁCS, G. Para uma ontologia do ser social v. I. São Paulo: Boitempo Editorial, 2012.

MARX, K. O capital l. III. Rio de J aneiro: Civilização Brasileira, 2008.

. Grundrisse. São Paulo: Boitempo Editorial, 2011.

. O capital l. I. São Paulo: Boitempo Editorial, 2013.

O capital l. II. São Paulo: Boitempo Editorial, 2014.

MONTORO, X. Capitalismo y economía mundial. Madri: Instituto Marxista de Economía, 2014. 
PAINCEIRA, J ; CARCANHOLO, M. Crise alimentar e financeira: a lógica especulativa atual do capital fictício. Anais do VI Colóquio Marx e Engels. Campinas: Cemarx Unicamp, 2009.

PAULANI, L. Autonomização das formas sociais e crise. Crítica Marxista, Campinas, n. 29, pp. 25-31, 2009.

PRADO, E.; PINTO, J . Limites do valor e do capitalismo. 2011. Disponível

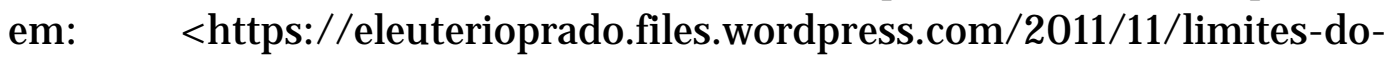
valor-e-do-capitalismo.pdf>, acessado em 6 jan. 2016.

ROSDOLSKY, R. Gênese e estrutura de O capital de Karl Marx. Rio de J aneiro: Eduerj/Contraponto, 2001.

SAAD-FILHO, A. O valor de Marx. Campinas: Ed. Unicamp, 2011.

Como citar:

MIRANDA, Flávio Ferreira de. Mercado mundial, dinheiro mundial e moeda inconversível: notas a partir de O capital. Verinotio - Revista online de Filosofia e Ciências Humanas, Rio das Ostras, v. 24, n. 2, pp. 5475, nov. 2018.

Data de envio: 17 out. 2017

Data de aceite: 31jul. 2018 